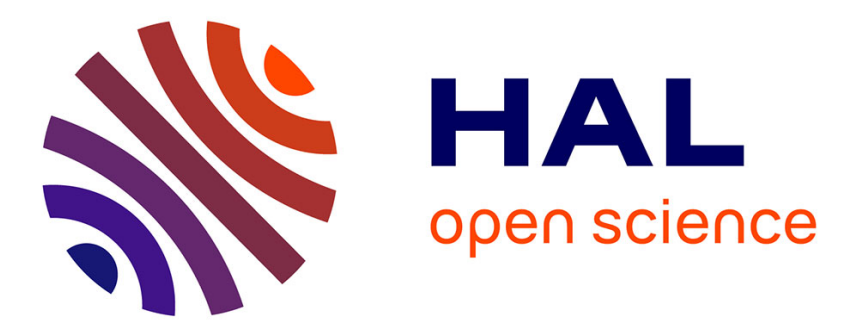

\title{
Doppler frequency conversion of microwaves by reflection from a relativistic beam front in a gas filled waveguide
}

J.M. Buzzi, H.J. Doucet, B. Etlicher, P. Haldenwang, A. Huetz, H. Lamain, C. Rouille

\section{To cite this version:}

J.M. Buzzi, H.J. Doucet, B. Etlicher, P. Haldenwang, A. Huetz, et al.. Doppler frequency conversion of microwaves by reflection from a relativistic beam front in a gas filled waveguide. Journal de Physique Lettres, 1977, 38 (20), pp.397-399. 10.1051/jphyslet:019770038020039700 • jpa-00231405

\section{HAL Id: jpa-00231405 https://hal.science/jpa-00231405}

Submitted on 1 Jan 1977

HAL is a multi-disciplinary open access archive for the deposit and dissemination of scientific research documents, whether they are published or not. The documents may come from teaching and research institutions in France or abroad, or from public or private research centers.
L'archive ouverte pluridisciplinaire HAL, est destinée au dépôt et à la diffusion de documents scientifiques de niveau recherche, publiés ou non, émanant des établissements d'enseignement et de recherche français ou étrangers, des laboratoires publics ou privés. 


\title{
DOPPLER FREQUENCY CONVERSION OF MICROWAVES BY REFLECTION FROM A RELATIVISTIC BEAM FRONT IN A GAS FILLED WAVEGUIDE (*)
}

\author{
J. M. BUZZI, H. J. DOUCET, B. ETLICHER, P. HALDENWANG, \\ A. HUETZ, H. LAMAIN and C. ROUILLE
}

Laboratoire de Physique des Milieux Ionisés $\left({ }^{* *}\right)$

Ecole Polytechnique, 91120 Palaiseau Cedex, France

(Reçu le 7 juillet 1977, accepté le 21 septembre 1977)

\begin{abstract}
Résumé. - La réflexion d'une onde électromagnétique est observée sur le front d'un faisceau d'électrons relativistes se propageant dans un guide d'onde contenant un gaz. La conversion de fréquence des ondes électromagnétiques de la bande $\mathrm{X}$ à la bande $\mathrm{K}_{\mathrm{a}}$ est en accord avec la valeur de la vitesse du front mesurée par sonde $\mathbf{B}_{\theta}$. La réflexion se produit durant le temps de montée du courant.
\end{abstract}

\begin{abstract}
Microwave reflection is observed on a relativistic electron beam front propagating into a gas filled waveguide. The frequency conversion from the incident $\mathbf{X}$ band electromagnetic waves and the reflected $K_{a}$ band signal is consistent with the value of the beam front velocity measured from time of flight using $B_{\theta}$ probes. The reflection is found to occur during the current rise time.
\end{abstract}

Beam front scattering of an electromagnetic wave has been suggested $[1,2]$ as a useful process, based upon the relativistic Doppler effect [3], for shifting the frequency of a short and intense microwave pulse towards infrared. In a recent experiment [4], microwave reflection on a relativistic electron beam has been observed and attributed to beam-front scattering. The associated relativistic Doppler shift bound experimentally was in agreement with a theoretical beam front velocity calculated using a free-streaming model for the description of the electron motion.

In the present work, microwave reflection is observed on a relativistic beam front propagating in a gas. The relation between the incident and reflected frequencies for various incident frequencies is measured experimentally and checked against the theoretical frequency shift predicted for the reflection in a waveguide. The beam-front velocity is also measured and compared to the value given by the frequency shift. Moreover the time of occurrence of the reflection is determined whith respect to the time dependence of the beam current.

The experimental configuration is shown in figure 1 .

$\left(^{*}\right)$ This work was supported by the Delegation Générale à la Recherche Scientifique et Technique, Décision d'Aide : 75-7-0121.

(**) Groupe de Recherche du C.N.R.S.

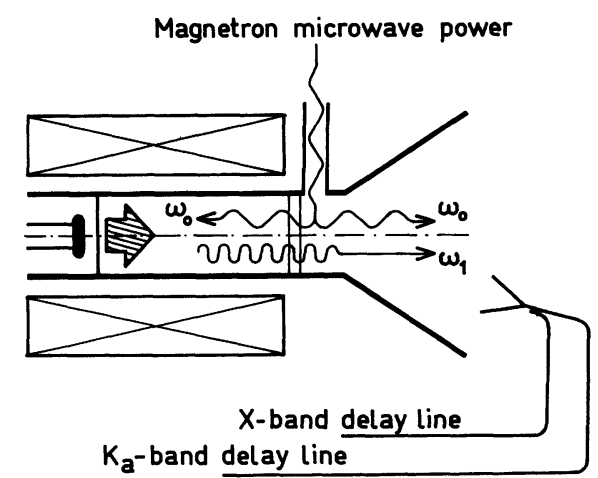

FIG. 1. - Experimental arrangement.

The electron beam is produced by a P.I. Pulserad $110 \mathrm{~A}$ device. The cathode is a $4 \mathrm{~cm}$ diam graphite disk located $1 \mathrm{~cm}$ from a $50 \mu \mathrm{m}$ thick titanium foil. The diode impedance is $43 \Omega$ and the diode voltage $750 \mathrm{kV}$. The electron beam propagates in an evacuated circular waveguide ( $42 \mathrm{~mm}$ diam) terminated by a Teflon window. The diode and the waveguide are immersed in an uniform static magnetic field. The waveguide is then connected to a rectangular circular $\mathrm{T}$ shape coupler and to a large conical horn.

The incident microwave signal is provided by a pulsed magnetron $(50 \mathrm{~kW}, 800 \mathrm{~ns}$ pulse duration, tunable between 8.6 and $9.6 \mathrm{GHz}$ ). The microwaves 
are injected into the circular waveguide through the rectangular - to - circular transition, which is a bidirectionnal $3 \mathrm{~dB}$ coupler, exciting each side of the circular waveguide with opposite-phase electric fields. Therefore, half of the magnetron power leaves the device through the conical antenna and is monitored by an X-band detector at the end of a $50 \mathrm{~m}$ delay line. The radiation pattern of the antenna has been measured and it agrees with the theoretical prediction for the $\mathrm{TE}_{01}$ mode. The second half of the magnetron power propagates towards the electron beam, mainly in the $T E_{01}$ mode. The reflected signal is measured in the $\mathrm{K}_{\mathrm{a}}$-band with crystal detectors and a $13 \mathrm{~m}$ delay line.

Frequency conversion from the reflection in a waveguide by a mirror moving at speed $v$ is given by [4] :

$$
f_{1}=f_{0}\left(1+2 \beta \beta_{\mathrm{g}}+\beta^{2}\right) \gamma^{2}
$$

with $\beta=v / c, \gamma=\left(1-\beta^{2}\right)^{-1 / 2}$ and $\beta_{\mathrm{g}}=v_{\mathrm{g}} / c$ where $v_{\mathrm{g}}$ is the group velocity of the incident wave. Since in our experiment, the incident wave lies in the $\mathrm{X}$ band and the expected reflected wave lies in the $K_{a}$ band, we see from eq. (1) that we need a value of $\beta$ close to 0.7 . We have chosen to adjust the value of the beam front velocity by changing the background gas pressure in the waveguide, holding constant all other parameters : the diode voltage, the current rise time and the magnetic field (5 kG).

In order to measure the beam front velocity, two $B_{\theta}$ probes were located on the surface of the waveguide with a spacing of $68 \mathrm{~cm}$ between probes. Timeof-flight measurements between the two probes allows the determination of an average beam front velocity. Figure 2 shows the variation of this beam front velocity as a function of the air pressure. Taking into account the delay in the cables, we have determined the beam current while measuring the beam front velocity with the two $B_{\theta}$ probes. As shown in figure 3 , this velocity measurement is made when the beam current in the drift tube is half of the peak value and we can thus measure the beam front velocity. Moreover in figure 2 we see that we reach the value $\beta \approx 0.7$, needed for the reflection, with about $400 \mu$ of air.

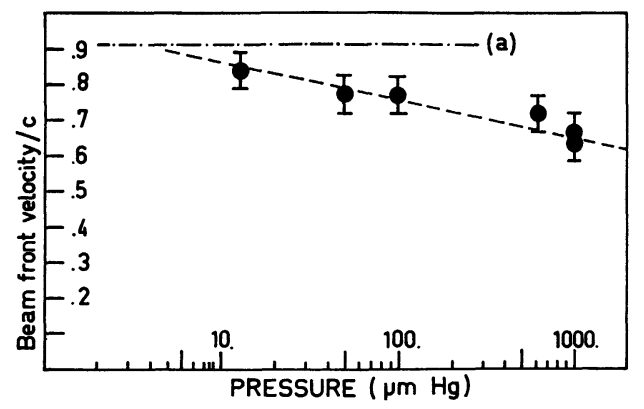

Fig. 2. - Variation of the beam front velocity as a function of the air pressure. The straight line (a) gives the value of $\beta$ deduced from the diode voltage.
Working with a background pressure of about $400 \mu$, without incident microwave power from the magnetron, we observe an emission in the $\mathrm{K}_{\mathrm{a}}$ band. Accurate measurements of the propagation delay in the cables and in the waveguides give us the time evolution of this emission with respect to the current (see Fig. 3). This emission occurs when the current is maximum in the waveguide.

When the magnetron signal is applied, other stronger spikes appear in the $\mathrm{K}_{\mathrm{a}}$ band and, as shown in figure 3 , before the emission of the beam, when the current reaches about $2 / 3$ of its maximum value. This signal is attributed to the reflection on the beam front. Since the $\beta$ values for the reflection in the $K_{a}$ band are very limited around 0.7 , from the results given in figure 4 , one should expect that the pressure is a very critical parameter.

As a matter of fact, the $K_{a}$ band detectors do not indicate any reflected signal when the pressure lies outside the range $350-450 \mu$. We have also varied the magnetron frequency $f_{0}$ and measured the reflected frequency $f_{1}$ with a $\mathrm{K}_{\mathrm{a}}$-band delay line. The results are presented in figure 5 and compared to the theore-

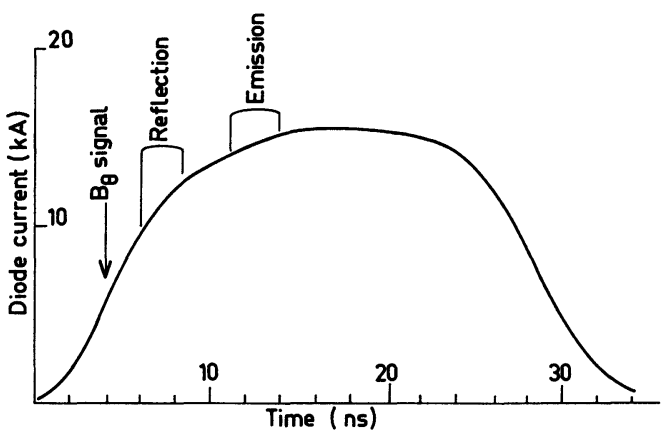

FIG. 3. - Timing of emission, reflection, diode current and $\mathbf{B}_{\theta}$ signal in the waveguide.

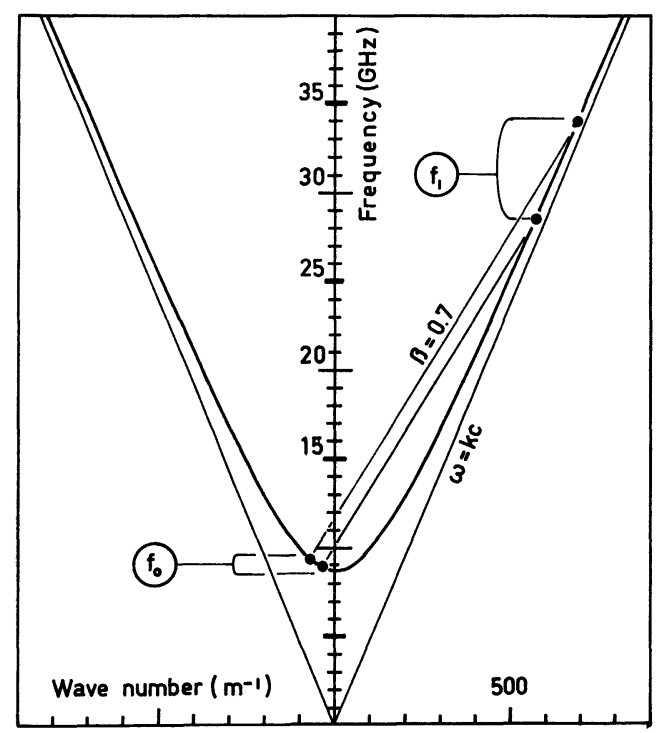

Fig. 4. - Frequency of the reflected signal as a function of the incident frequency predicted for $\beta=0.7$ in the case of the $\mathrm{TE}_{01}$ mode. 


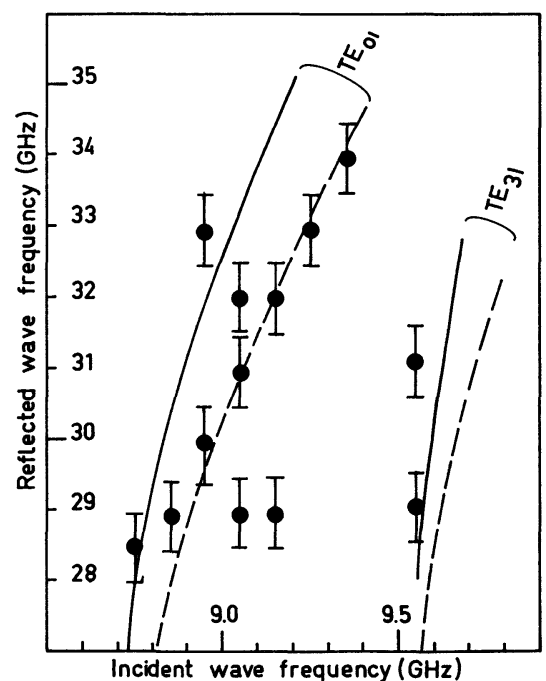

Frg. 5. - Experimental variation of the reflected signal as a function of the incident frequency. The full lines corresponds to predicted variation for $\beta=0.7$ and the dotted lines for $\beta=0.68$ for the modes $\mathrm{TE}_{01}$ and $\mathrm{TE}_{31}$. Error bars indicate uncertainities due to finite delay-line length and duration of the microwave pulse.

tical curves given by eq. (1) for the $\mathrm{TE}_{01}$ and $\mathrm{TE}_{31}$ modes. Fairly good agreement is found for $\beta$ close to 0.7 . Therefore, the corresponding velocity of the mirror is close to the beam front velocity.

Note that for one given magnetron frequency one observes very short reflected pulses with slightly different frequencies for about 3 ns. This suggests that the reflecting beam front is the result of a transient phenomena.

In conclusion, we have observed the reflection of microwaves on a relativistic electron beam front propagating in a gas. The mirror velocity deduced from the relativistic Doppler shift for various incident frequencies agrees with the beam front velocity measured with $B_{\theta}$ probes. We have also shown that the reflection occurs during the rise time of the beam current. However, the reflected power has not yet been measured and the reflection coefficient is unknown. The specific mechanism for the change of the waveguide cut off due to the beam front in a gas has not been determined. These two points, particularly the importance of the ionization front, are presently under investigation. If ionization processes participate in the reflection mechanism, the reflection coefficient could be rather small [5].

Acknowledgments. - The authors would like to express their thanks to Professor S. P. Schlesinger for his encouragement, fruitful discussions on the subject and help in the design of the microwave components. They also thank Dr. Mourier for discussions on the experiments and for the possible use of a Thomson CSF magnetron.

\section{References}

[1] Granatstein, V. L., Parker, R. K., Sprangle, P., International Topical Conference on Electron Beam Research and Technology. Vol. II (1975) 401, Sandia Laboratories Report SAND76-5122.

Pasour, J. A., Parker, R. K., Granatstein, V. L., HernDON, M., SCHLESINGER, S. P., Second International Conference on Submillimeter waves. Porto Rico, dec. 1976, p. 140. S. Perkowitz, Editor, IEEE Cat $\mathrm{n}^{\circ} 76 \mathrm{CH} 1152-8$ MTT. To be published in IEEE Transactions on Microwaves Theory and Techniques.

[2] DOUCET, H. J., Advisory Group Meeting on Experimental Aspects of Laser and Electron Beam produced Thermonuclear Plasmas. Trieste, Italy, August 1975.

Doucet, H. J., Lamain, H., Rouillé, C., Faure, J. L., Buzzi, J. M., Camarcat, N., Bull. Am. Phys. Soc. 20 (1975) 1290.

Buzzi, J. M., Doucet, H. J., Faure, J. L., Lamain, H., Rouillé,
C., Cabé, J. C., Delvaux, J., Jouys, J. C., Peugnet, C. RoCHE, M., Second International Conference on Submillimeter waves, Porto Rico, dec. 1976, p. 247, S. Perkowitz, Editor (IEEE Cat No 76 CH1152-8 MTT), to be published in IEEE transactions on Microwaves Theory and Techniques.

[3] LANDeCKer, K., Phys. Rev. 86 (1952) 852.

[4] Granatstein, V. L., Sprangle, P., Parker, R. K., Pasour, J., Herndon, M., Schlesinger, S. P., Seftor, J. L., Phys. Rev. A 14 (1976) 1194.

[5] Lampe, M., Ott, E., Manheimer, W. M., Kainer, S., in the Proceedings of the Second International Conference on Submillimeter Waves, Porto Rico, déc. 1976, p. 144, S. Perkowitz (Editor, IEEE cat $\mathrm{n}^{\circ}$ 76) CH1152-8 MTT, to be published in IEEE transactions on Microwaves Theory and Techniques. 